\title{
Arbeidsmarktprognoses Twente 2017-2022
}

Citation for published version (APA):

Peeters, T., \& Cörvers, F. (2018). Arbeidsmarktprognoses Twente 2017-2022. ROA. ROA Fact Sheets No. 008B https://doi.org/10.26481/umarof.2018008B

Document status and date:

Published: 01/01/2018

DOI:

10.26481/umarof.2018008B

Document Version:

Publisher's PDF, also known as Version of record

\section{Please check the document version of this publication:}

- A submitted manuscript is the version of the article upon submission and before peer-review. There can be important differences between the submitted version and the official published version of record.

People interested in the research are advised to contact the author for the final version of the publication, or visit the DOI to the publisher's website.

- The final author version and the galley proof are versions of the publication after peer review.

- The final published version features the final layout of the paper including the volume, issue and page numbers.

Link to publication

\footnotetext{
General rights rights.

- You may freely distribute the URL identifying the publication in the public portal. please follow below link for the End User Agreement:

www.umlib.nl/taverne-license

Take down policy

If you believe that this document breaches copyright please contact us at:

repository@maastrichtuniversity.nl

providing details and we will investigate your claim.
}

Copyright and moral rights for the publications made accessible in the public portal are retained by the authors and/or other copyright owners and it is a condition of accessing publications that users recognise and abide by the legal requirements associated with these

- Users may download and print one copy of any publication from the public portal for the purpose of private study or research.

- You may not further distribute the material or use it for any profit-making activity or commercial gain

If the publication is distributed under the terms of Article $25 \mathrm{fa}$ of the Dutch Copyright Act, indicated by the "Taverne" license above, 


\section{Arbeidsmarktprognoses Twente 2017-2022}

Tim Peeters

Frank Cörvers

\section{ROA Fact Sheet}

ROA-F-2018/8B

Researchcentrum voor Onderwijs en Arbeidsmarkt | ROA Research Centre For Education and the Labour Market / ROA 


\section{Arbeidsmarktprognoses Twente 2017-2022}

\author{
Inleiding
}

Als onderdeel van het Project Onderwijs-Arbeidsmarkt (POA) stelt het ROA sinds 2013 tweejaarlijkse regionale arbeidsmarktprognoses op die tegemoet komen aan de toenemende belangstelling voor regionale arbeidsmarktinformatie. Binnen dit kader past ook voorliggende factsheet met arbeidsmarktprognoses voor de arbeidsmarktregio Twente. Deze prognoses bestrijken de periode 2017-2022 en worden weergegeven voor 24 opleidingscategorieën die verdeeld zijn over zes opleidingsniveaus. Waar mogelijk worden de prognoses vergeleken met deze voor Overijssel als geheel, en wordt eveneens een relatie gelegd met zowel de sector- als opleidingsspecialisatie van de werkgelegenheid in de verschillende regio's. ${ }^{I}$ Zie ook Tekstbox I voor definities van de in deze factsheet gebruikte variabelen.

\section{Prognoses en actuele arbeidsmarktcijfers naar} opleidingsniveau

De arbeidsmarkregio Twente bevat iets meer dan de helft van de bevolking van Overijssel. Dit heeft tot gevolg dat de prognoses en actuele arbeidsmarktgegevens voor deze regio dikwijls niet veel afwijken van deze voor de provincie.

Tabel I toont de prognoses en actuele arbeidsmarktcijfers voor zes opleidingsniveaus in Twente. Geaggregeerd over alle opleidingsniveaus worden voor schoolverlaters en werkzoekenden in Twente de komende zes jaar redelijke arbeidsmarktperspectieven verwacht, met een totale ITA $(\mathrm{I}, \mathrm{O2})$ die nipt minder gunstig is dan die van Overijssel en de twee andere arbeidsmarktregio's. Voor elk opleidingsniveau wordt bovendien een lagere uitbreidingsvraag voorzien. Ook is de instroom gemiddeld hoger, wat deels een gevolg is van het relatief grote aandeel jongeren. Net als in de provincie Overijssel kennen basisonderwijs, vmbo en wo de beste baanperspectieven, maar basisonderwijs en vmbo bieden tevens slechte loopbaanperspectieven. In vergelijking met de rest van Overijssel en Nederland als geheel kent Twente bovendien een lager percentage werkenden onder schoolverlaters van het basisonderwijs/vmbo en havo/vwo, en zijn ze beduidend vaker werkzaam in flexibele banen met tijdelijke contracten. In Twente wijzen de recente cijfers dus op een aanzienlijk slechtere arbeidsmarktpositie dan over het algemeen in Nederland.

I Voor de arbeidsmarktontwikkelingen van de hele provincie Overijssel, zie de factsheet met nummer ROA-F-2018/8.
Opvallend is dat de verwachte ITA voor basisonderwijs en vmbo (0,9I) gunstiger is dan voor wo $(0,95)$. Beide opleidingsniveaus kennen een zeer grote vervangingsvraag, maar de arbeidsmarktinstroom vanuit het basisonderwijs of vmbo (veelal voortijdig schoolverlaters van vmbo, mbo of havo/vwo) is aanzienlijk kleiner. Deze gunstige perspectieven dienen echter met enige voorzichtigheid geïnterpreteerd te worden. Een aanzienlijk deel van de vraag naar personen met basisonderwijs of vmbo als opleidingsachtergrond heeft namelijk betrekking op kleine banen. Dit kan afgeleid worden van het relatief lage gemiddeld aantal gewerkte uren per week $(24,8)$ en het hoge aandeel van studenten en scholieren $(25 \%)$. Bovendien gaat het vaak om flexibele banen met weinig doorgroeimogelijkheden. Enerzijds blijkt dit uit het lage percentage dat voltijds en vast in dienst is. Anderzijds komt dit ook tot uiting in het slechte loopbaanperspectief. De variabele "typering loopbaan", die per opleidingsniveau de loongroei tussen ca. 25 en 45 jaar (berekend voor Nederland als geheel) weergeeft in 2016, is namelijk het minst gunstig voor laagopgeleiden, en het meest gunstig voor havo/vwo. ${ }^{2}$ Deze laatste groep bestaat mogelijk deels uit mensen die geen hogere opleiding hebben afgemaakt omdat ze door hun persoonlijke capaciteiten uitstekende kansen op de arbeidsmarkt hadden.

Verder is van belang dat de groep van laagopgeleiden met basisonderwijs of vmbo heel heterogeen is: niet alleen scholieren, maar ook voortijdig schoolverlaters zonder startkwalificatie (minimaal mbo 2 of havo), schoolverlaters van het speciaal onderwijs en arbeidsgehandicapten. Bij het aangegeven goede arbeidsmarktperspectief is geen rekening gehouden met de mogelijke sociale, fysieke en cognitieve beperkingen van mensen binnen deze groep.

\section{Sectorspecialisatie}

Zoals blijkt uit figuur I, verschilt de sectorspecialisatie van de arbeidsmarktregio Twente voor de meeste sectoren niet erg veel van deze van Overijssel (zie oranje stippen). In de metaalindustrie heeft Twente met voorsprong de meest uitgesproken specialisatie, maar ook in de andere industriesectoren kent Twente een beduidend groter aandeel werkenden dan voor Nederland. De werkgelegenheidsaandelen van de sectoren cultuur en sport en informatie en communicatie zijn daarentegen bijna de helft kleiner dan in Nederland. Ook de welzijnssector,

2 De indicator voor loopbaanperspectief wordt berekend aan de hand van het verschil in bruto uurloon van werkenden in de leeftijdsgroep 20-29 jaar en 40-49 jaar. Voor een argumentatie, zie Fouarge, D., Kriechel, B., \& Dohmen, T. (2014), Occupational sorting of school graduates: The role of economic preferences, Journal of Economic Behavior \& Organization, 106, 335-351. 
Tabel 1

Arbeidsmarktprognoses (2017-2022) en actuele arbeidsmarktcijfers (2015-2016) Twente naar opleidingsniveau*

\begin{tabular}{|c|c|c|c|c|c|c|c|}
\hline & bo/vmbo & havo/vwo & mbo $2 / 3$ & mbo 4 & hbo & wo & totaal \\
\hline \multicolumn{8}{|l|}{ Prognoses } \\
\hline Uitbreidingsvraag (\%) & 0,6 & 0,5 & 0,7 & 0,7 & 0,5 & 0,9 & 0,6 \\
\hline Vervangingsvraag (\%) & 4,0 & 1,5 & 2,2 & 1,9 & 2,9 & 3,9 & 2,8 \\
\hline Arbeidsmarktinstroom (\%) & 2,0 & 1,7 & 4,3 & 3,0 & 3,7 & 3,2 & 3,1 \\
\hline ITA & 0,91 & 1,04 & 1,11 & 1,07 & 1,03 & 0,95 & 1,02 \\
\hline Typering ITA & goed & redelijk & matig & matig & redelijk & goed & redelijk \\
\hline Typering loopbaan (euro) & slecht & zeer goed & matig & redelijk & redelijk & goed & - \\
\hline \multicolumn{8}{|l|}{ Actuele indicatoren } \\
\hline Bruto uurloon (euro) ${ }^{* *}$ & 13,7 & 17,3 & 17,7 & 19,2 & 25,1 & 34,7 & - \\
\hline Werkenden & 66.000 & 24.500 & 59.000 & 57.000 & 66.000 & 27.000 & 301.000 \\
\hline Werkzaamheid (\%) & 46 & 61 & 67 & 78 & 78 & 85 & 64 \\
\hline Werkloosheid (\%) & 5 & 6 & 5 & 5 & 4 & 2 & 5 \\
\hline Vast werk (\%) & 66 & 58 & 86 & 87 & 88 & 94 & 80 \\
\hline Voltijds (\%) & 38 & 30 & 52 & 50 & 57 & 67 & 50 \\
\hline Wekelijkse arbeidsduur (uur) & 24,8 & 23,3 & 32,0 & 32,0 & 33,3 & 36,2 & 30,4 \\
\hline Leeftijd werkenden (jaar) & 39,4 & 34,4 & 42,6 & 41,9 & 41,1 & 43,3 & 40,9 \\
\hline Student/scholier (\%) & 25 & 40 & 2 & 5 & 4 & 1 & 11 \\
\hline
\end{tabular}

"Prognoses als gemiddeld jaarlijks percentage van de werkzame beroepsbevolking in 2016; actuele indicatoren als percentage van de werkzame, totale of potentiële beroepsbevolking 2015-2016 (zie Tekstbox 1), tenzij anders aangegeven

Lonen voor Nederland in 2016

Figuur 1

Sectorspecialisatie Twente ten opzichte van Nederland (2015-2016)

Landbouw, bosbouw en visserij Voedings- en genotmiddelenindustrie Chemische industrie Metaalindustrie Overige industrie Energie Bouwnijverheid Detailhandel Groothandel Vervoer en opslag Horeca

Informatie en communicatie Financiële dienstverlening en onroerend goed Special istische zakelijke dienstverlening Verhuur en overige zakelijke dienstverlening Openbaar bestuur en overheidsdiensten

Onderwijs

Zorg

Welzijn

Cultuur sport en recreatie

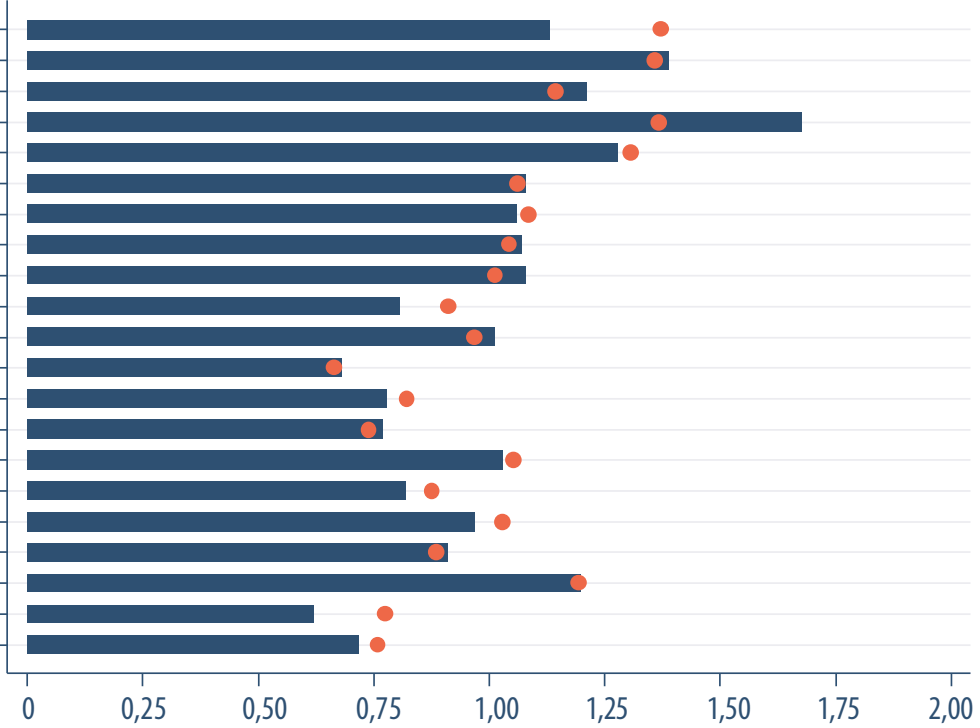

Overige dienstverlening, huishoudens en extraterritoriale organisaties

\begin{tabular}{|ll|}
\hline & Sectorspecialisatie Twente \\
\hline & Sectorspecialisatie Overijssel
\end{tabular}


Tekstbox 1 Definities kernbegrippen

\begin{tabular}{|c|c|}
\hline Variabele & Definitie \\
\hline Uitbreidingsvraag & $\begin{array}{l}\text { Vraag naar nieuwe arbeidskrachten die ontstaat door de groei van de werkgelegenheid. Als er sprake is van een werkgelegenheidsdaling, is de } \\
\text { uitbreidingsvraag negatief. }\end{array}$ \\
\hline Vervangingsuraag & $\begin{array}{l}\text { Vervangingsvraag is de vraag naar nieuwe arbeidskrachten die ontstaat door bijvoorbeeld pensionering, (tijdelijke) uittreding vanwege zorgtaken, } \\
\text { arbeidsongeschiktheid, beroepsmobiliteit of doorstroom naar een andere opleiding. }\end{array}$ \\
\hline Arbeidsmarktuitstroom & De som van de vervangingsvraag en de negatieve uitbreidingsvraag. \\
\hline Arbeidsmarktinstroom & $\begin{array}{l}\text { De arbeidsmarktinstroom is het verwachte aanbod van nieuwe arbeidskrachten op de arbeidsmarkt. Deze is gebaseerd op de verwachte uitstroom van } \\
\text { schoolverlaters uit het initiële dag-, deeltijd-, niet-reguliere voltijdonderwijs en de beroepsgerichte volwasseneneducatie. Het weergegeven aanbod in de } \\
\text { figuren } 2 \text { en } 3 \text { is de instroom. Gecorrigeerd voor mobiliteitsstromen tussen arbeidsmarktregio's. }\end{array}$ \\
\hline Baanopeningen & $\begin{array}{l}\text { Baanopeningen zijn de totale vraag naar nieuwkomers op de arbeidsmarkt, zoals deze is bepaald door de werkgelegenheidsgroei (positieve uitbreidingsvraag) } \\
\text { en de vervangingsvraag. In de figuren } 2 \text { en } 3 \text { is dit de vraag naar arbeid. }\end{array}$ \\
\hline ITA & $\begin{array}{l}\text { Indicator Toekomstige Arbeidsmarktperspectief (ITA) van schoolverlaters en werkzoekenden. Deze indicator is gelijk aan een deling van het verwachte aanbod } \\
\text { door de verwachte vraag tot 2022. Naarmate de waarde van de ITA hoger ligt, is er sprake van een slechter arbeidsmarktperspectief. Een waarde tussen 1,01 en } \\
1,05 \text { duidt op een evenwichtssituatie. }\end{array}$ \\
\hline Typering ITA & $\begin{array}{l}\text { Een kwalitatieve beschrijving van de ITA. ITA } \leq 0,85 \text { wordt als "zeer goed" getypeerd, ITA }>0,85 \text { en } \leq 1,00 \text { als "goed", ITA }>1,00 \text { en } \leq 1,05 \text { als "redelijk", ITA }> \\
1,05 \text { en } \leq 1,15 \text { als "matig" en ITA }>1,15 \text { als "slecht". }\end{array}$ \\
\hline Typering loopbaan & $\begin{array}{l}\text { Het bruto uurloon van werkenden in de leeftijdsgroep } 40-49 \text { jaar ten opzichte van het bruto uurloon van werkenden in de leeftijdsgroep } 20-29 \text { jaar. Gemiddelde } \\
\text { cijfers voor Nederland in } 2016 \text {. }\end{array}$ \\
\hline Bruto uurloon & $\begin{array}{l}\text { Gemiddeld bruto uurloon van werknemers in euro's. Enquête Beroepsbevolking (EBB) gekoppeld aan het Sociaal Statistisch Bestand (SSB) van het jaar } 2016 . \\
\text { Gemiddelde ciffers voor Nederland in } 2016 .\end{array}$ \\
\hline Werkenden & Minimaal 1 uur werkzaam per week en in de leeftijd 15-74. Cijfers op basis van de Enquête Beroepsbevolking van het CBS. \\
\hline Werkzaamheid & Het percentage werkzaam is de werkzame beroepsbevolking als percentage van de potentiële beroepsbevolking (iedereen ouder dan 15 en jonger dan 75 jaar). \\
\hline Werkloosheid & $\begin{array}{l}\text { Percentage personen die geen betaald werk hebben, wel recent hebben gezocht en daarvoor direct beschikbaar zijn als percentage van de totale } \\
\text { beroepsbevolking (werkzaam en werkloos). }\end{array}$ \\
\hline Vast werk & Personen met een vast dienstverband. Percentage op basis van werknemers in de werkzame beroepsbevolking. \\
\hline Voltijds & Voltijdarbeid betreft personen die minstens 35 uur per week werkzaam zijn. Percentage op basis van de werkzame beroepsbevolking. \\
\hline Leeftijd & Gemiddelde leeftijd. \\
\hline Uren & Gemiddeld aantal uren werk per week. \\
\hline Student/scholier & Percentage van de werkenden met maatschappelijke positie student/scholier. \\
\hline Sectorspecialisatie & $\begin{array}{l}\text { De verhouding tussen het aandeel van het aantal werkenden in een sector in een bepaalde regio ten opzichte van het aandeel van die sector in Nederland. Een } \\
\text { sectorspecialisatiecoêfficiënt groter dan } 1 \text { impliceert dat het aandeel werkenden in de desbetreffende sector in de regio groter is dan in Nederland als geheel. }\end{array}$ \\
\hline Opleidingsspecialisatie & $\begin{array}{l}\text { De ratio van het aandeel personen met een bepaalde opleidingscategorie die wonen in een bepaalde regio ten opzichte van het aandeel van die } \\
\text { opleidingscategorie in het Nederlandse totaal. Indien de specialisatiecoëfficiënt voor een opleidingscategorie groter is dan 1, betekent dit dat de regio in } \\
\text { verhouding tot Nederland een groter aandeel van mensen met deze opleiding kent. }\end{array}$ \\
\hline
\end{tabular}


detailhandel en groothandel zijn in Twente relatief groot. Daar waar Overijssel als geheel een sterke specialisatie heeft in landbouw, bosbouw en visserij, geldt dit ten slotte slechts in beperkte mate voor Twente.

\section{Arbeidsmarktperspectieven naar opleidingscategorie}

Figuren 2 en 3 geven per opleidingscategorie de verwachte verhouding weer tussen arbeidsvraag en -aanbod over de prognoseperiode 2017-2022. De meeste mbo-opleidingen worden gekenmerkt door een overaanbod, in het bijzonder mbo $2 / 3$ groen en mbo $2 / 3$ zorg en welzijn. Deze laatste opleidingscategorie heeft bovendien als gevolg van een zeer groot aanbod binnen Overijssel uitsluitend in Twente een slechte ITA-typering.

In tegenstelling tot de mbo-prognoses, hebben schoolverlaters van alle opleidingscategorieën binnen het wo, met uitzondering van wo onderwijs, dan weer allemaal goede arbeidsmarktperspectieven, met de beste vooruitzichten voor wo gedrag en maatschappij en wo landbouw en natuur. In tegenstelling tot haar wo-tegenhanger, is hbo onderwijs echter de richting met de beste vooruitzichten binnen de hbo-opleidingscategorieën. De overige hbo-categorieën laten een gemengd beeld zien, met de minst gunstige perspectieven voor afgestudeerden van hbo economie (matig). De perspectieven voor hbo als opleidingsniveau zijn bovendien in Twente zwakker dan in de andere arbeidsmarktregio's.

De technische opleidingen worden gekenmerkt door een relatief omvangrijke vraag naar wo- en hbo-gediplomeerden, maar hebben slechts matige en redelijke perspectieven voor respectievelijk mbo $2 / 3$ en mbo 4 techniek. Een vrij groot geschat arbeidsaanbod van mbo 4 -gediplomeerden is overigens de reden dat deze opleidingscategorie in Twente zwakkere vooruitzichten heeft dan in de andere arbeidsmarktregio's. Ondanks de sterke aanwezigheid van industriële sectoren in Twente impliceren deze matige vooruitzichten voor de technische mbo-opleidingen dat deze sectoren verwacht worden weinig wervingsproblemen te zullen ondervinden bij het invullen van technische vacatures op middelbaar niveau. Het omgekeerde geldt echter voor hbo en wo techniek.

\section{Relatie arbeidsmarktperspectieven en specialisatie naar opleiding}

De relatie tussen de ITA voor de verschillende opleidingscategorieën en de mate waarin die opleidingen in Twente relatief meer of minder voorkomen ten opzichte van Nederland wordt weergegeven in Figuur 4 Gezien het grote aandeel van Twente in het provinciale bevolkingsaantal, lijkt deze figuur vrij sterk op Figuur 4 voor Overijssel. Een grotere specialisatie in een bepaalde opleidingscategorie gaat meestal samen met een hogere ITA en dus een slechter arbeidsmarktperspectief.

Twente heeft een relatief groot aandeel van de meeste mbo 2/3 en mbo 4-opleidingscategorieën, welke bovendien allemaal een ITA hebben die groter is dan I. Schoolverlaters van het basisonderwijs/vmbo en havo/vwo zijn er dan weer in verhouding evenveel als in Nederland, maar de ITA voor basisonderwijs/vmbo is aanzienlijk gunstiger dan die voor havo/vwo. De welzijnssector, waarin Twente een relatief grote werkgelegenheid heeft, zal naar verwachting voor de meeste opleidingsniveaus weinig rekruteringsproblemen kennen aangezien de ITA's en relatieve aandelen ten opzichte van Nederland van mbo $2 / 3$ zorg en welzijn, mbo 4 zorg en welzijn en hbo gezondheidszorg groter zijn dan I.

\section{Conclusie}

Gegeven het belangrijke aandeel van Twente in het Overijsselse inwonersaantal, lijken de prognoses voor deze arbeidsmarktregio vaak op deze van de provincie. Op geaggregeerd niveau worden voor schoolverlaters en werkzoekenden in Twente redelijke arbeidsmarktperspectieven voorzien tijdens de prognoseperiode 2017-2022. Als gevolg van een relatief beperkte uitbreidingsvraag en iets grotere arbeidsmarktinstroom is deze ITA echter nipt minder gunstig dan die van de andere twee arbeidsmarktregio's. Middelbaar geschoolden hebben slechts matige perspectieven, terwijl de vooruitzichten voor hbo en wo respectievelijk matig en goed zijn. Personen afkomstig van het basisonderwijs/vmbo en havo/vwo kennen in deze arbeidsmarktregio bovendien een lagere werkzaamheid dan in Nederland als geheel, en hebben vaker een flexibele baan.

Voor de meerderheid van de mbo-opleidingen wordt een overaanbod van schoolverlaters en werkzoekenden verwacht, in het bijzonder voor mbo $2 / 3$ groen en mbo $2 / 3$ zorg en welzijn. Voor wo-opleidingen worden daarentegen voornamelijk vraagtekorten voorzien. Verder zijn de prognoses voor technisch geschoolden afhankelijk van het opleidingsniveau, met goede perspectieven voor hbo- en wo techniek, maar slechts matige en redelijke vooruitzichten voor respectievelijk mbo $2 / 3$ - en mbo 4 techniek. De voor Twente belangrijke industriesectoren zullen daarom naar verwachting slechts deels met knelpunten te maken krijgen. 


\section{Figuur 2}

Vraag en aanbod voor opleidingscategorieën lager/middelbaar (beroeps)onderwijs, Twente (2017-2022)

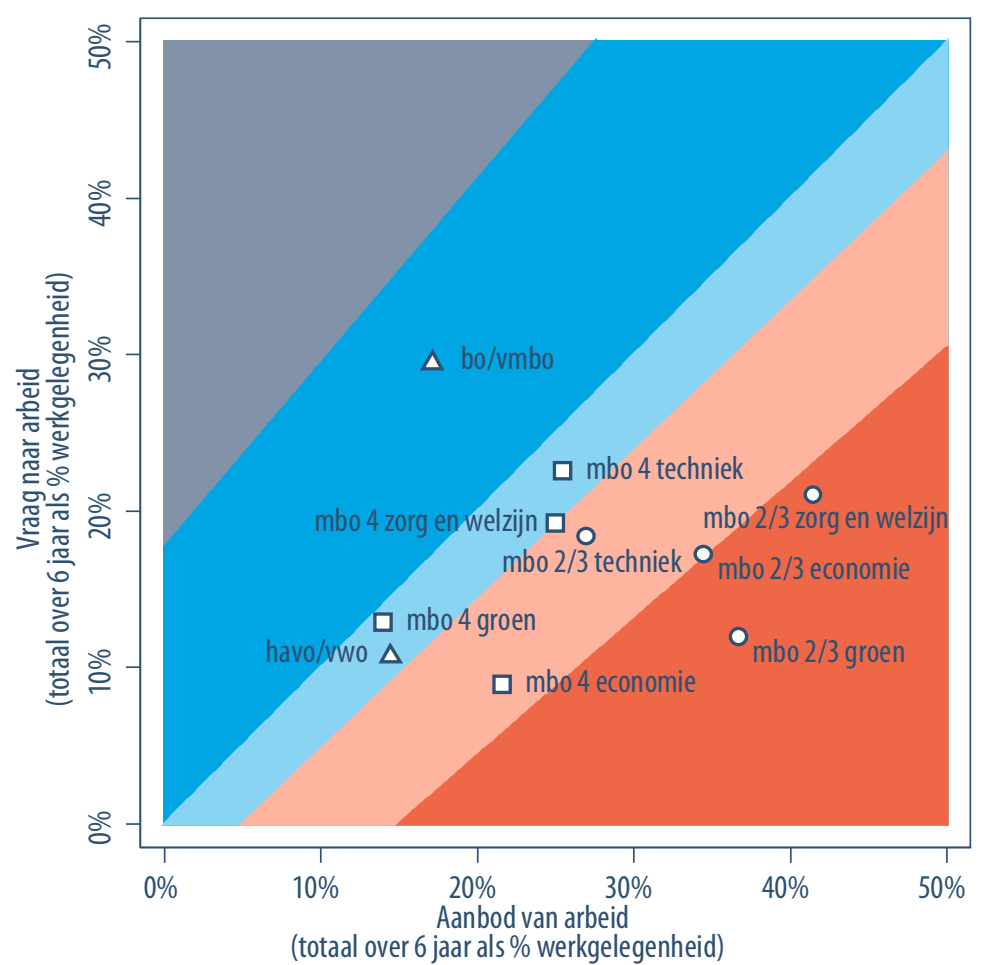

\begin{tabular}{|c|l|}
\hline & $\begin{array}{l}\text { ITA-typering zeer goed } \\
\text { ITA-typering goed } \\
\text { ITA-typering redelijk } \\
\text { ITA-typering matig }\end{array}$ \\
& ITA-typering slecht \\
& bo/vmbo en havo/vwo \\
$\Delta$ & mbo 2/3 \\
\hline $\mathbf{0}$ & mbo 4 \\
\hline
\end{tabular}

Figuur 3

Vraag en aanbod voor opleidingscategorieën hoger onderwijs, Twente (2017-2022)
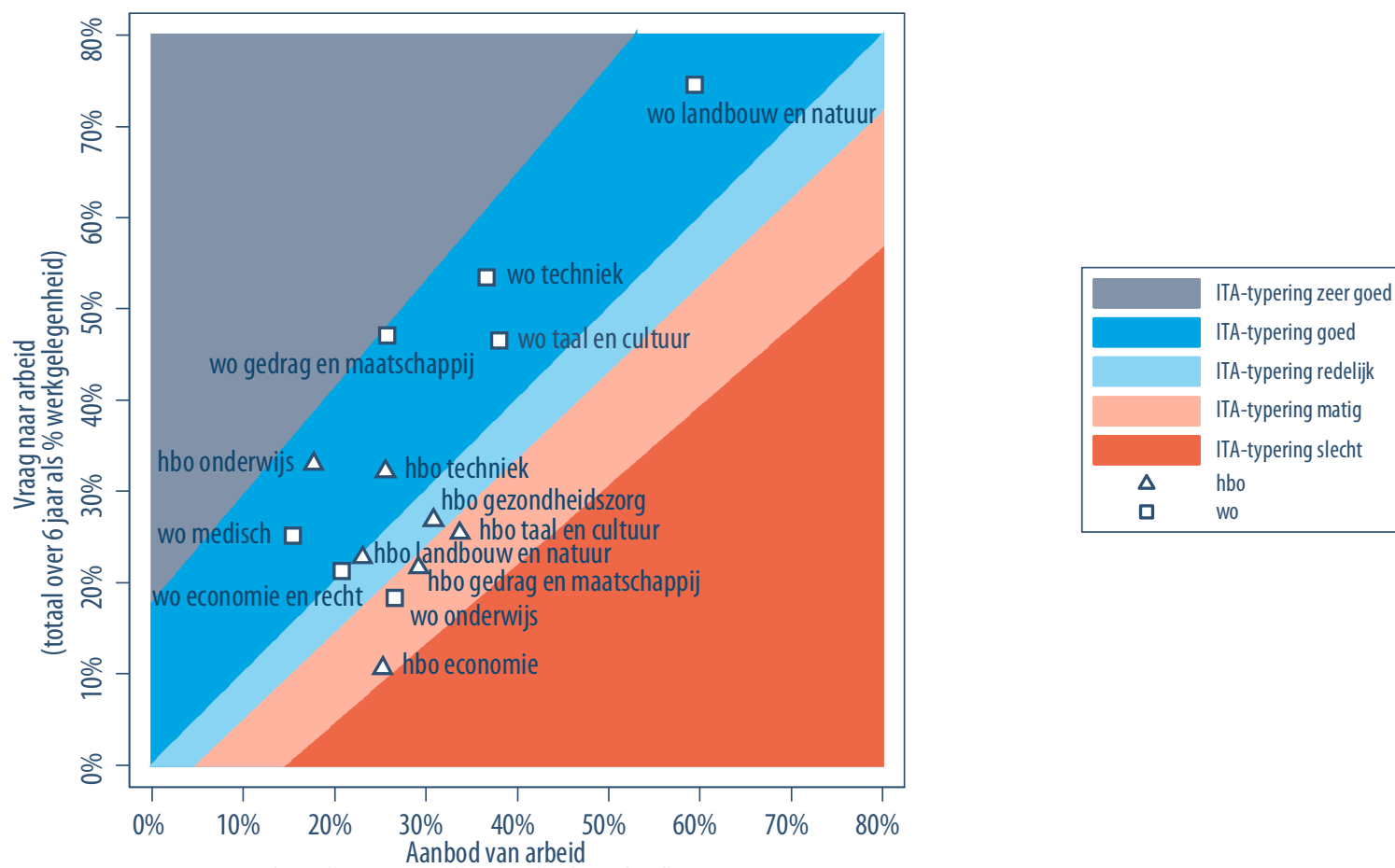

(totaal over 6 jaar als \% werkgelegenheid) 
Figuur 4

Arbeidsmarktperspectieven (ITA) versus specialisatie naar opleidingscategorie, Twente

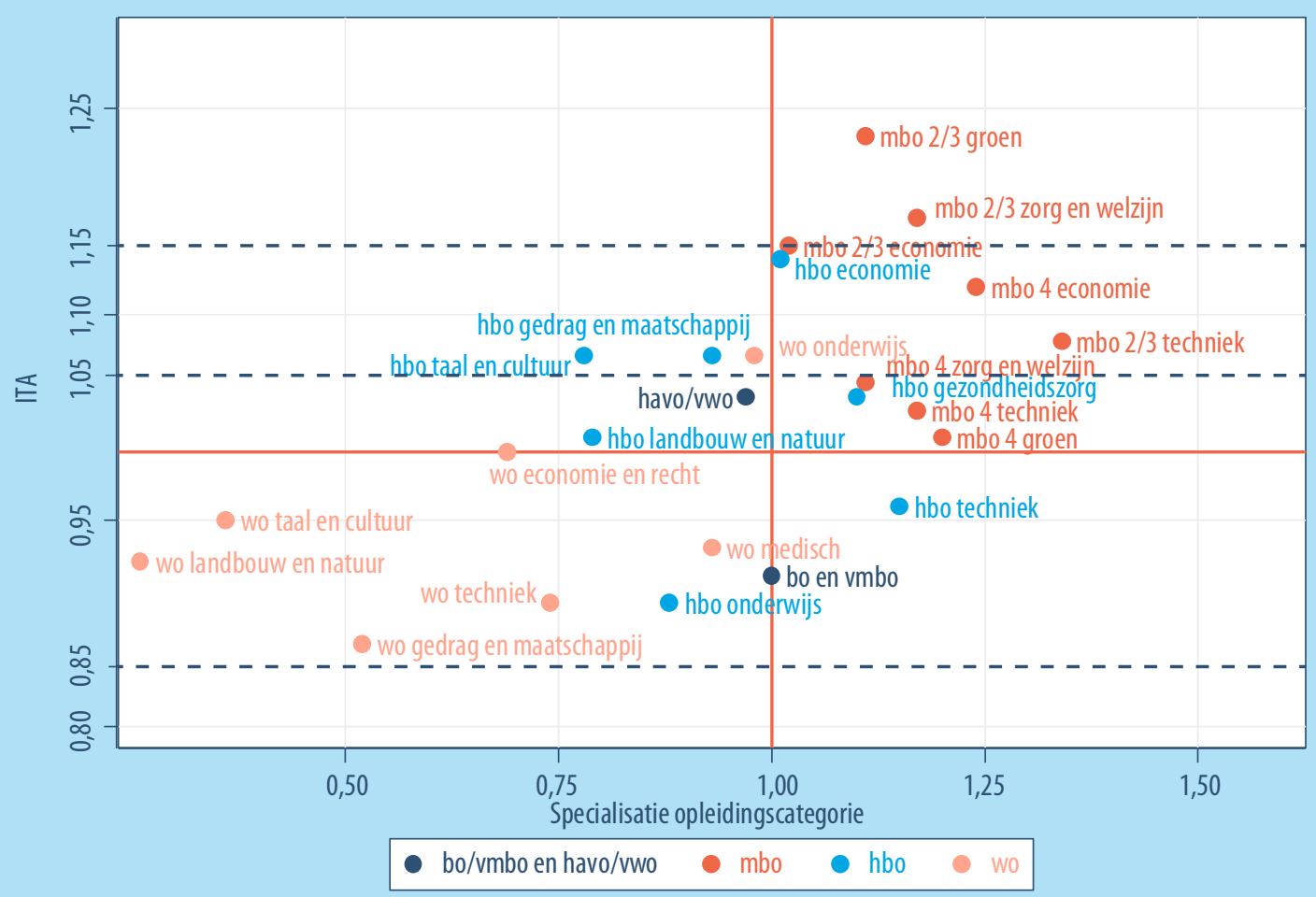




\section{Colofon}

( ) Researchcentrum voor Onderwijs en Arbeidsmarkt Niets uit deze uitgave mag op enige manier worden verveelvoudigd zonder voorafgaande schriftelijke toestemming van de directeur van het ROA.

Researchcentrum voor Onderwijs en Arbeidsmarkt

Maastricht University

School of Business and Economics

secretary-roa-sbe@maastrichtuniversity.nl

www.roa.n

\section{Vormgeving}

ROA secretariaat, Maastricht

maart 2018 